\title{
A review of building occupants adaptive behavior in buildings of China
}

\author{
Song Pan ${ }^{1, a}$, Lang Xie ${ }^{1, b}$, Shen Wei ${ }^{2, c}$, Yunmo Wang ${ }^{1, c}$, \\ Chuanqi $\mathrm{Xu}^{1, \mathrm{c}}$, Xinru Wang ${ }^{1, \mathrm{c}}$, Yanan Zhang ${ }^{1, \mathrm{c}}$ \\ ${ }^{1}$ Building Environment and Energy Applications Engineering, \\ Beijing University of Technology, China \\ ${ }^{2}$ Faculty of Engineering and Environment, Northumbria University, UK \\ a1565000454@qq.com, b809944286@qq.com, shen.wei@northumbria.ac.uk
}

\begin{abstract}
Keywords: building performance, occupants adaptive behaviors, behavior models, building performance simulation

Abstract. In order to realize the sustainable development of society, building energy consumption has become a global concern. In buildings, occupants adaptive behaviors that means how to use the buildings have an very important influence on the building energy use. The researches of occupants adaptive behaviors have been carried out for more than 30 years in Europe, including England, Switzerland, Denmark and so on. In past 10 years, many Chinese scholars also started to study on this field. This paper reviewed the articles of occupants adaptive behaviors in china and summerized the current development situations then discussed the proper development direction in the future that can give some advises and references for the future study.
\end{abstract}

\section{Introduction}

With the rapid development of economy and the increasing energy consumption, sustainable development has become one of the hottest topic in the world. At present, the building energy consumption accounts for about $40 \%$ of the total energy consumption society ${ }^{[1]}$. Therefore, in order to realize sustainable development, reducing building energy consumption has become a global task. In many buildings, indoor thermal environment regulation is mainly implemented through some traditional personnel adaptive behavior ,such as switch windows/doors, adjust air conditioning system temperature set point, adjust the shading devices, adjust the thickness of the clothes and so on. Therefore, adaptive behavior (later called human behavior ) will directly affect the whole building energy consumption. Many European scholars have carried out exploration and discussion on this subject in order to better understand the adaptive behavior of the building users ${ }^{[2-6]}$. There's some of these studies about which factors will affect the people behavior of building ${ }^{[7-8]}$; some of these studies about how to modeling human behavior more accurately ${ }^{[9-10]}$;some of these about how to change human behavior ${ }^{[11-12]}$.

At the end of 2013, the International Energy Agency (IEA) has approved a new International cooperation projects which last 4 years, ANNEX 66: Definition and Simulation of Occupant Behavior in Buildings ${ }^{[23]}$. The main task of this project is to explore how to better measure, modeling and simulation the human behavior in the building. At present, the researchers form more than 23 countries have already said that they have to participate in the project. This article sum up China's existing related research including the research direction, research methods, research ideas and results. And analyzes the deficiencies and limitations in the existing research.

\section{Domestic research present situation about human behavior}

At present, the people behavior research is generally divided into the following three parts: the first part is the analysis of actual measurement about human behavior, which mainly includes the influence factors of the human behavior and the degree of influence human behavior on 
building energy consumption; The second part is the mathematical modeling of human behavior in order to improve human behavior quantification in building simulation software ;and the third part is the simulation of human behavior, it is important to explore the relationship between human behavior and building energy consumption. This paper will summarize the domestic human behavior research separately for these three areas.

\section{The analysis of actual measurement about human behavior}

To assess the adaptive behavior of people inside the building, the first to understand the factors that affect human behavior. This requires to conduct the actual testing on building insiders. In this regard, there have been some related research in China.

Li Nan ${ }^{[14]}$ has carried on the actual survey of human behavior of residents in Yangtze river basin in 2007 and 2008. A total of 1046 questionnaires were filled out in the course of the investigation, of which 939 copies are valid questionnaires. The results show that the main behavior of residents in hot summer and cold winter region of China is as follows: (1) The summer air conditioning open way of $67.2 \%$ is determined by the sense of hot and cold : air conditioning will be turned on if feel hot, turned off if feel cold and turned on again if feel hot ; There are $32.8 \%$ is always open. The average time of using air conditioning by most users is 4-8 hours, which mainly concentrated in the evening; the setting temperature mainly concentrated in two interval, within the range of two respectively $23-24{ }^{\circ} \mathrm{C}$ and $25-26{ }^{\circ} \mathrm{C}$; (2) $61.6 \%$ of the users don't open the window due to the use of air conditioning during the summer, $32.8 \%$ of the users will not open the window in general, but they occasionally feel boring when they need to improve indoor air quality by open the windows. (3)The winter air conditioning open way of $62.6 \%$ is determined by the sense of hot and cold : air conditioning will be turned on if feel cold, turned off if feel hot and turned on again if feel cold. There are $37.4 \%$ is always open when somebody in their house. Most heating behavior last more than half month, and it is mainly concentrated in the three time periods : in the evening, late at night and in the morning. The setting temperature is $20{ }^{\circ} \mathrm{C}$ or more generally. (4) $49.1 \%$ of users occasionally open the windows in winter, $27.2 \%$ of users regularly open windows, 23.7 percent of survey users to always keep windows closed. This shows that most people will choose to use the windows in the winter to improve indoor air quality.

In summary, the current domestic human behavior study measured mainly by two methods: (1) Questionnaire (2) The instrument measurements. The existing research can be roughly grouped into the following three parts. First, in terms of the climate characteristics of research, the main research is based on the use of air conditioning in summer and open-window behavior, there are some studies on the behavior of the winter heating equipment and open-window behavior in transition seasons. Secondly, in terms of the geographical position of the research object, the mainly measured object concentrate in the vicinity of the Yangtze River basin, with hot summer and cold winter area based. Finally, in terms of building types, mainly directed against both office and residential building types.

\section{Modeling of human behavior}

In the aspects of modeling human behavior in buildings, Chinese scholars have begun to use the method of random to quantitative description of human behavior impact on building energy consumption. By combining the building energy consumption simulation software and scientific method to quantitatively describe the human behavior in buildings, to achieve more accurate predict building energy consumption and formed a new simulation analysis method. On the other hand human behavior definition platform has been put forward, it presents a clear concept of human behavior study. Human behavior has also established a standard definition of construction documents, by way of example, we can verify the validity of the document ${ }^{[19]}$.

Li Nan ${ }^{[14]}$ investigated a workers' dormitory' 78 household electricity consumption in August, the dormitory locate in the hot summer and cold winter area. He used multi-factor variance of the 
SPSS statistical analysis software analysis method analyses the six factors, including impact households window open a window ventilated, night time situation, family structure, air conditioning setting temperature, air conditioning switch behavior, the housing area, and found that air conditioning set temperature and the air conditioning switch, air conditioning open time and the air conditioning set temperature, air conditioning open time and the impact on air conditioning energy consumption exist between family structure interaction.

\section{Simulation of human behavior}

Due to the current research on the people behavior modeling of China rarely, so the research on the human behavior simulation is rarely. But if we can better consider the possible future impact of building user behavior on building performance (the built environment and building energy) at the design stage, it will greatly reduce the uncertainty human behavior on the part of the architectural design caused. Therefore, to better simulate human behavior on the architectural design has a critical influence.

\section{Conclusion}

The paper summarized current Chinese studies in terms of human behavior in the building and analyzed by three aspects: (1) Measurement and analysis of human behavior; (2) mathematical modeling of human behavior; (3) Simulation of human behavior. Through analysis, the main conclusions are as follows:

1: The purpose of study human behavior is to study the impact of human behavior on building energy consumption through the field research, the software simulation and example demonstration system method, thus the building energy consumption model is put forward under the consideration for human behavior, in order to reduce value gap between simulation results and the actual measured results. But there is no related research can very scientifically quantitative impact of human behavior on building energy consumption in China;

2: At present, the research on the human behavior in China is still in the preliminary exploration stage. By review article, it can be seen that most of China's research is measurement research and rarely more in-depth exploration, such as modeling and simulation research. This is mainly due to the lack of basic data. On the other hand, Chinese scholars in terms of the Measurement of human behavior involved is not very comprehensive, for example, the lack of shade, indoor conditions (carpet or wood floors), staff positions, dress grade, social factors and considerations unexpected situations. These need to be considered in future studies to provide protection for the correctness of the modeling and simulation of the future;

3: The modeling research of human behavior in China mostly concentrate in the summer, seldom consider other seasons. And research is conducted in the Yangtze river basin, thus makes the human behavior model has limitations. Open-window behavior modeling research, for example, due to China's vast territory, the north-south across multiple climate zone, stretching from coast to inland regions, various climate types, different living habits around, unbalanced economic development between regions, life level difference is very big, these could affect the applicability of the developed model. So we need to have the universality of development model for more research and exploration。

\section{Reference}

[1] EC 2013. Report from the commission to the European parliament and the council. Brussels: European Commission.

[2] WEI, S., BUSWELL, R. \& LOVEDAY, D. 2013. Factors affecting 'end-of-day' window position in a non-air-conditioned office building. Energy and Buildings, 62, 87-96.

[3] MCCARTNEY, K. J. \& NICOL, F. J. 2002. Developing an adaptive control algorithm for Europe. Energy and Buildings, 34(6), 623-635. 
[4] HALDI, F. \& ROBINSON, D. 2009b. Interactions with window openings by office occupants. Building and Environment, 44, 2378-2395.

[5] YUN, G. Y. \& STEEMERS, K. 2008. Time-dependent occupant behaviour models of window control in summer. Building and Environment, 43(9), 1471-1482.

[6] HERKEL, S., KNAPP, U. \& PFAFFEROTT, J. 2008. Towards a model of user behaviour regarding the manual control of windows in office buildings. Building and Environment, 43(4), 588-600.

[7] WEI, S., JONES, R. \& DE WILDE, P. 2014. Driving factors for occupant-controlled space heating in residential buildings. Energy and Buildings, 70, 36-44.

[8] FABI, V., ANDERSEN, R. V., CORGNATI, S. \& OLESEN, B. W. 2012b. Occupants' window opening behaviour: A literature review of factors influencing occupant behaviour and models. Building and Environment, 58, 188-198.

[9] WEI, S., BUSWELL, R. \& LOVEDAY, D. A comparison of alternative occupant classification approaches for the modelling of window opening behaviour in office buildings In: NCEUB, ed. 8th Windsor Conference: Counting the Cost of Comfort in a changing world, 10-13 April 2014a Cumberland Lodge, Windsor, UK.

[10] HALDI, F. \& ROBINSON, D. 2008a. A comparison of alternative approaches for the modelling of window opening and closing behaviour. Windsor 2008 Conference: Air Conditioning and the Low Carbon Cooling Challenge. Cumberland Lodge, Windsor, UK: NCEUB.

[11] DE WILDE, P., PAHL, S., HAMZA, N., WEI, S., JONES, R. \& ABOHELA, I. 2013. Using building simulation to drive changes in occupant behaviour: A pilot study. Building Simulation 2013 Conference. Chambery, France.

[12] KIM, Y. K. \& ALTAN, H. 2013. Using dynamic simulation for demonstrating the impact of energy consumption by retrofit and behavioural change Building Simulation 2013 Conference. Chambery, France.

[13] Tsinghua University, IEA-EBC ANNEX proposal, 2014

[14] Li Nan. In hot summer and cold winter area personnel behavior research on the influence of the energy consumption of residential buildings [D]. Chongqing: chongqing university Bachelor's degree thesis for heating, gas, ventilation and air conditioning engineering, 2011.

[15] Qiu Shaohui, an-gui li etc. Energy saving: xi 'an natural ventilation rate of residential window open investigation[C].2008 Hvac academic conference proceedings, 2008:111-114.Toward

[16] Zhang Jian. Building and high impact study of office users to open a window ventilated action

[J]. Journal of central China Building, 2011, (8) : 50-53.

[17] Chen Weihuang. Summer thermal comfort in hot summer and cold winter area condition and residents window behavior research [D]. Hunan: hunan university of masters Bachelor's degree thesis for heating, gas, ventilation and air conditioning engineering, 2009. [18] yi-wen jian, liu jian, etc. The house of $\mathrm{CO} 2$ concentration and the relationship between people behavior experimental study [J]. Journal of hvac, 2012,(09) vol [19]Zhou Peng, Steven. Yan, ycas. People behavior standard definition and case analysis [C]. Architectural society of China Air conditioning branch, professional committee of China refrigeration institute of air conditioning heat pump, 2010 national hvac annual conference proceedings, 